\title{
A Review of Computational Studies of Temperature Separation Mechanism in Vortex Tube
}

\author{
H.R. Thakare, Y.R. Patil and A.D. Parekh
}

\begin{abstract}
The Ranque Hilsch Vortex Tube (RHVT) is a very simple device well known for its phenomenal temperature separation effect. With a single input of compressed gas, the tube simultaneously produces two different streams of gas one being hotter and other being colder than input gas. Over the years, different theories have attempted to explain this effect without achieving any universal agreement. Small size of RHVT presents considerable difficulties towards predicting temperature, pressure and flow field inside it. This is where Computational Fluid Dynamics (CFD) analysis comes to the aid of researchers. Many of researchers have attempted such analysis using turbulence models such as The Standard $k-\varepsilon$

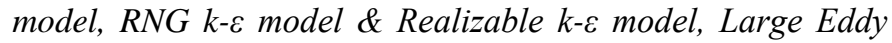
Simulation Technique (LES) etc. This paper attempts to present a review of such recent qualitative studies carried out on RHVT using CFD. Care has been taken to explore diversified parameters related to flow physics inside RHVT, instead of being monotonous one. This review is expected to help future researches in the related domain.
\end{abstract}

Keywords--- CFD, RHVT, Turbulence Model, Temperature Separation

\section{INTRODUCTION}

$\mathrm{T}$ HE vortex tube is a device without moving mechanical parts, which converts a flow of compressed gas, initially homogeneous in temperature, into two separate flows - one of a low total temperature and the other of a high one. Such a separation of the flow into two temperature regimes is termed as the Temperature or Energy Separation Effect. The vortex tube contains the following parts: one or more inlet nozzles, a vortex generator, a cold and hot end orifice, a hot end control valve and a tube. The phenomenon of temperature separation in a swirling vortex flow was discovered in 1930s by Georges $\mathrm{J}$. Ranque. Hence it is called as the Ranque effect and has been a popular research topic within the scientific community. Ranque proposed that compression and expansion effects are the main reasons for the temperature separation in the tube. Later, the geometrical parameters and performance optimization of the tube were investigated by Hilsch. He

H.R. Thakare, M. Tech. Student, Mechanical Engineering Department, S.V.N.I.T., Surat, India. E-mail: thakare.hitesh@gmail.com

Y.R. Patil, M.E. Student, Mechanical Engineering Department, K. J. Somaiya College of Engineering, Mumbai, India. E-mail: patil.yogita2008@gmail.com

Dr.A.D. Parekh, Associate Professor, Mechanical Engineering, Department, S.V.N.I.T., Surat, India.E-mail:adp@med.svnit.ac.in added the effect of inner friction to the Ranque's model of compression and expansion.

Vortex tubes have widely been used in various applications where compactness, safety, and low equipment cost are basic factors: heating and cooling applications, gas liquefaction, separation of gas mixtures, drying of gases, using in chemical industry, snow making etc. Nowadays, RHVTs are produced by different commercial companies with a wide range of applications.

Even though a significant interest has been created by these applications, the physical phenomenon responsible for the temperature separation is still being debated. One of the obstacles to investigations of RHVT is the lack of substantial published literature review. An important aspect of any research work on RHVT should be to collect together a significant mass of published literature.

Many experimental studies have been carried on RHVT, however, very few of them have been able to predict profiles of pressure, temperature and velocity vectors inside RHVT. After the advent of modern digital high speed computation facilities, a number of Computational Fluid Dynamics (CFD) studies have been carried out to understand the physics of RHVT. This paper is an attempt to present collective information about such numerical analysis of RHVT.

\section{IMPORTANT DEFINITIONS}

This section presents some important terms commonly used in study of RHVT.

- Cold Mass Fraction: - It is given as the ratio of mass of gas leaving through cold exit to the total mass of gas entering through the nozzle.

$$
\mu_{\mathrm{c}}=\frac{\dot{\mathrm{m}}_{\mathrm{c}}}{\dot{\mathrm{m}}_{\mathrm{in}}} \text {, Also, } 0 \leq \mu_{\mathrm{c}} \leq 1
$$

- Cold and Hot End Temperature Difference:Cold end temperature difference is defined as the difference between temperature of gas at inlet and temperature of gas at cold exit.

$$
\Delta \mathrm{T}_{\mathrm{c}}=\mathrm{T}_{\mathrm{in}}-\mathrm{T}_{\mathrm{c}}
$$

Hot end temperature difference is defined as the difference between temperature of gas at inlet and temperature of gas at hot exit.

$$
\Delta \mathrm{T}_{\mathrm{h}}=\mathrm{T}_{\mathrm{h}}-\mathrm{T}_{\mathrm{in}}
$$

- Coefficient of Performance (COP):-

It is defined as the ratio of refrigerating or cooling effect obtained to the work input supplied.

$$
\mathrm{COP}=\frac{\mathrm{RE}}{\mathrm{W}_{\text {in }}} \text {, where, } \mathrm{RE}=\dot{\mathrm{m}}_{\mathrm{c}} \times \mathrm{C}_{\mathrm{pc}} \times\left(\mathrm{T}_{\mathrm{in}}-\mathrm{T}_{\mathrm{c}}\right)
$$


Where, $T_{i n}$ is the inlet flow temperature, $T_{c}$ is the cold flow temperature and $\mathrm{T}_{\mathrm{h}}$ is the hot flow temperature, $\dot{\mathrm{m}}_{\mathrm{c}}$ is the mass of cold flow, $\mathrm{C}_{\mathrm{pc}}$ is specific heat of gas.

\section{NUMERICAL STUDIES ON RHVT}

N. F. Aljuwayhel et al. [1] analyzed the RHVT using twodimensional axi-symmetric CFD model \& two different turbulence models: the standard $\mathrm{k}-\varepsilon$ model with a turbulent Prandtl number equal to unity and RNG k- $\varepsilon$ model. The RNG $\mathrm{k}-\varepsilon$ model is similar to the standard $\mathrm{k}$-e model with exception that it includes the effect of swirl on the turbulence intensity and calculates, rather than assumes, a turbulent Prandtl number. It also has an additional term included in the energy equation to improve the analysis of rapidly strained flows.

In CFD model, the flow entered the vortex tube axially with a significant tangential velocity, unlike the experimental arrangement where it entered radially at outer diameter. Aljuwayhel et al. [1] justified that numerical stability of the CFD model was improved when the axial inlet geometry was used \& also facilitated the parametric studies. For a cold mass fraction of 0.3 , the standard $\mathrm{k}-\varepsilon$ model predicted a $27.2 \mathrm{~K}$ temperature drop for the cold flow (relative to the inlet temperature) whereas the RNG k- $\varepsilon$ model predicted only 20.7 $\mathrm{K}$. This significant difference reflects the likely impact of the large centrifugal pressure gradients on the turbulence intensity.

To identify the source of energy transfer and mechanism of temperature separation, they divided vortex tube into three control volumes: 1 . flow exiting via hot end 2 . Flow exiting via cold end 3. Flow circulating near the inlet nozzle (the recirculating region); this flow is the secondary flow which was noted by Ahlborn and Gordon [15].

Result of numerical model indicated that swirl velocity increased in the radial direction, except very near the outer wall. Negative axial velocity near the centerline and positive near the outer diameter, indicated the recirculating nature of the flow. The angular velocity as a function of radius at four axial locations indicated that it decreased in the radial direction, except very near the centerline as shown in Fig. 1. The magnitude of radial velocity was found to be very less in the entire domain, compared to that of swirl and axial velocity.

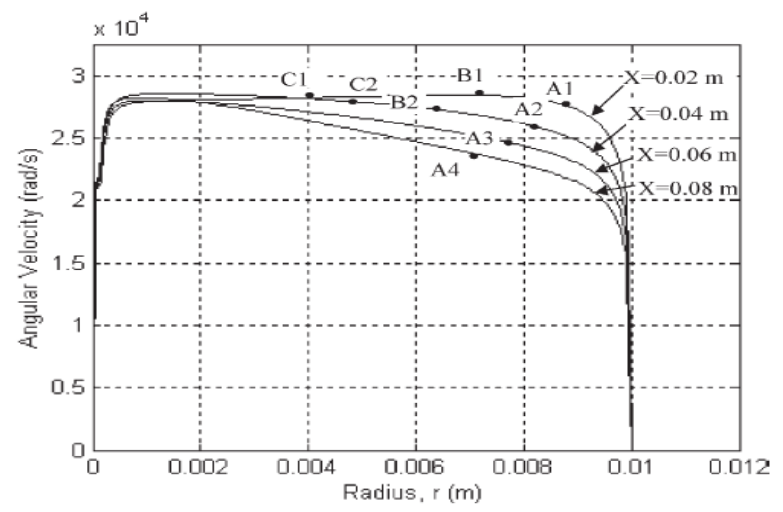

Figure 1: Angular Velocity in Radial Direction at Different Axial Locations [1]

As shown in Fig. 2, static temperature decreased in the radial direction except very near the tube inlet.

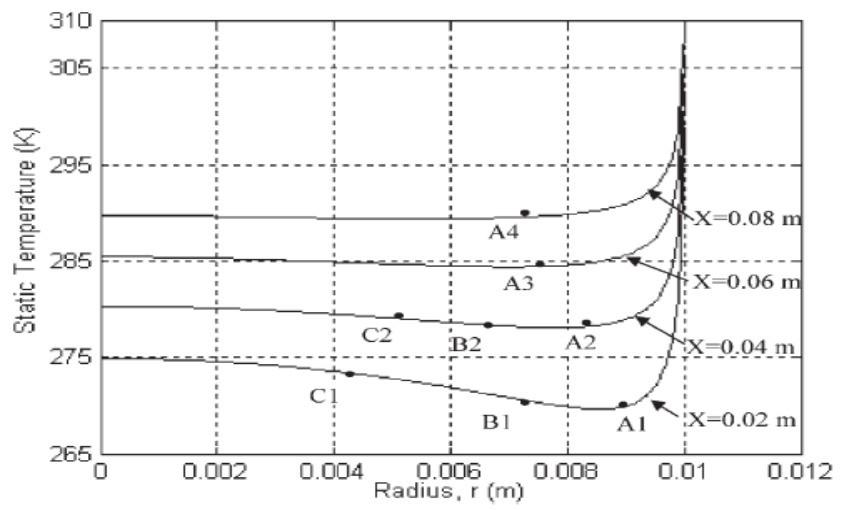

Figure 2: Variation of Static Temperature in Radial Direction at Different Axial Locations [1]

Parametric study carried out regarding length of RHVT indicated that the cold flow travelled a critical length of 22.5 $\mathrm{cm}$, before returning towards the cold end, and over which most of energy transfer occurred. However, any further increase in the RHVT length did not improve the temperature separation. Also, increasing the diameter of RHVT reduced the gradients of angular velocity, which are responsible for tangential work transfer. This resulted in reduced energy separation.
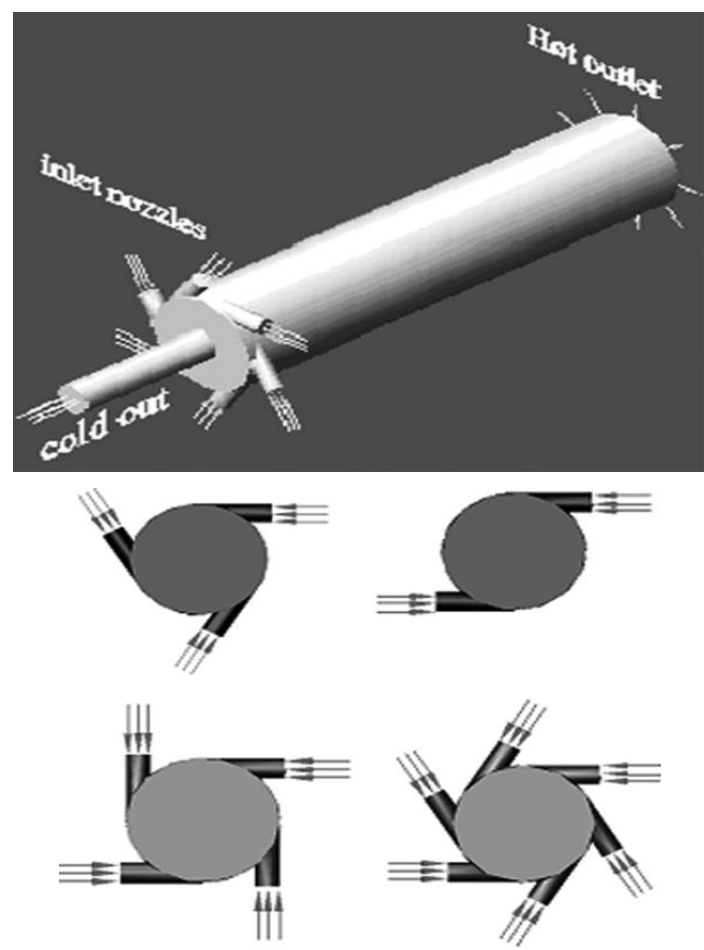

Figure 3: Arrangement of Inlet Nozzles in RHVT with 3, 2, 4 and 6 nozzles [2]

Rahim Shamsoddini et al. [2] used 3D CFD Model to investigate the effect of the nozzles number on the flow and power of cooling of RHVT, shown in Fig. 3. Authors successfully used RNG k- $\varepsilon$ model. Air was used with compressible fluid and ideal gas assumption. QUICK scheme was used to discretize the convective terms. Equations of momentum and energy were solved simultaneously using coupled procedure. 
Analysis streamlines indicated that, in all cases of nozzles number, streamlines next to the wall travel toward the hot end, while streamlines alongside the axis turn toward the cold end. The pattern of streamlines approaches that of the axisymmetric solution as the number of nozzles is increased. It implies that axisymmetric assumption is correct only in the case of the large number of nozzles, shown in Fig. 4.

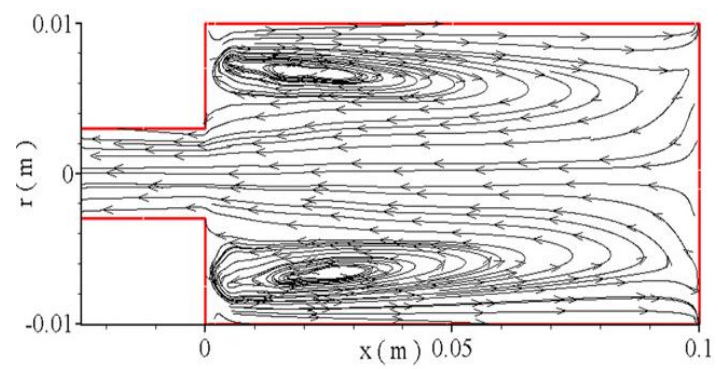

(a)

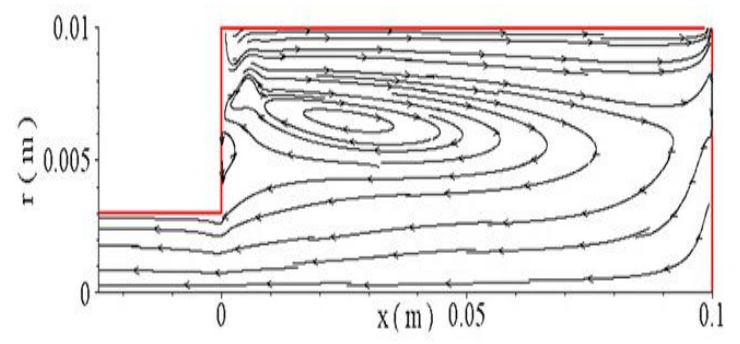

(b)

Figure 4: Comparison of streamlines (a) Eight Nozzles (b) Axisymmetric Solution [2]

Also, at the exit of nozzles inlets, vortices were observed. The number and size of them decreases as the nozzles number increased. It was concluded that these vortices play major role in confining and mixing cold and hot flow inside RHVT. Temperature decreases radially inward at each of these vortices. Reduced number of these vortices results in less mixing of central cold flow with peripheral hot flow. With increase in nozzle number, the cooling power increase significantly. Power of cooling in case of 8 nozzles case was $8.7 \%$ more than that in 2 nozzles.

H M Skye et al. [3] used $10.6 \mathrm{~cm}$ length of an Exairß 708 slpm $(25 \mathrm{scfm})$ vortex tube. A mesh consisting of 25,000 grid points was used with node concentration near the orifices. At low cold fractions, CFD model predicted that reversed flow will occur at the cold exit, shown in Fig. 5.

As shown in Fig. 6, the model consistently under predicted the cold and hot temperature separation by approximately 16 and $4 \mathrm{~K}$, respectively. Both the experimental data and the model show maximum power separation with a cold fraction of about 0.65 , depicted in Fig. 7.

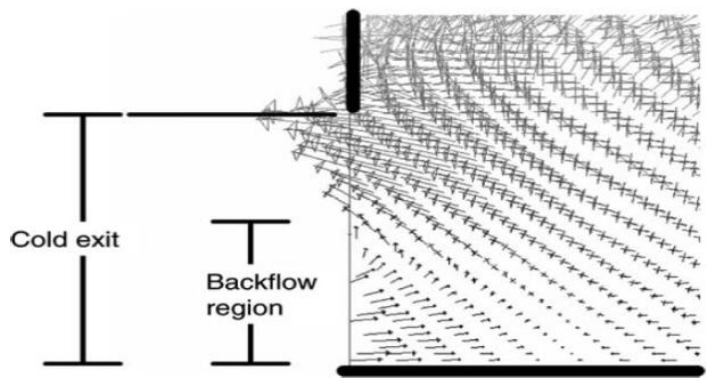

Figure 5: Reversed flow through cold end at low value of cold mass fraction [3]

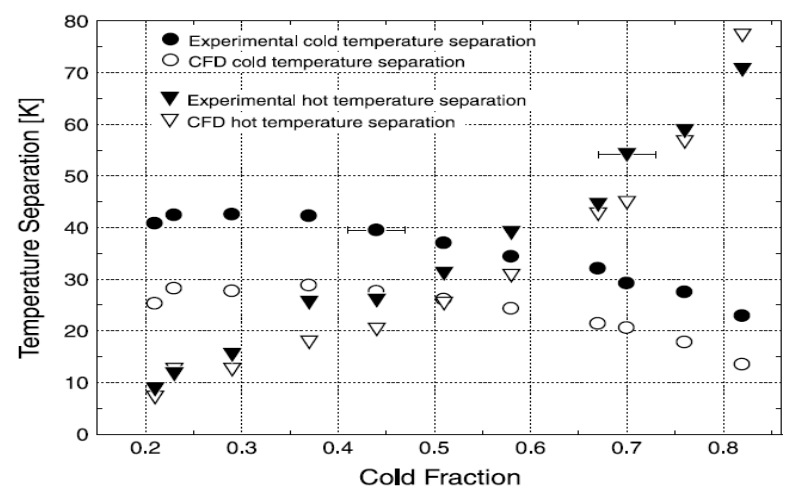

Figure 6: Comparison of Experimental and CFD Results of Temperature Separation [3]

Both experimental and CFD results for cooling power indicated that maximum power separation occurs at cold mass fraction of 0.65. CFD model still under predicted the separation effect, however qualitative agreement was achieved in the results.

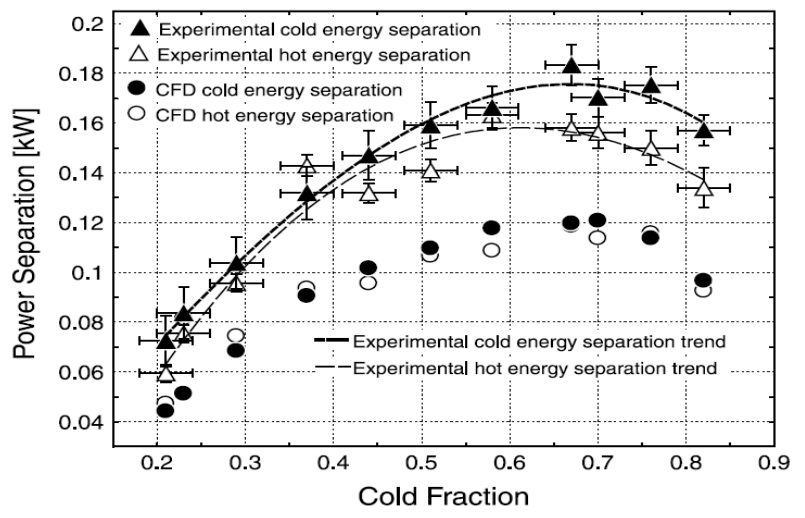

Figure 7: Experimental and CFD Results of Power Separation [3]

When RSM model was used, FLUENT was unable to predict the temperature separation. In this case, the direction of cold flow and hot flow was reversed.

Tanvir Farouk et al. [4] used Large Eddy Simulation (LES) technique to predict the flow field and temperature separation in RHVT. The maximum axial velocity $\left(\mathrm{u}_{\mathrm{x}}\right)$ was found to exist near the tube wall, where the direction of the flow was towards hot end. The flow along the axis was directed towards the cold end exit. The maximum value of the axial velocity decreased with increasing axial distance (Fig. 8). 


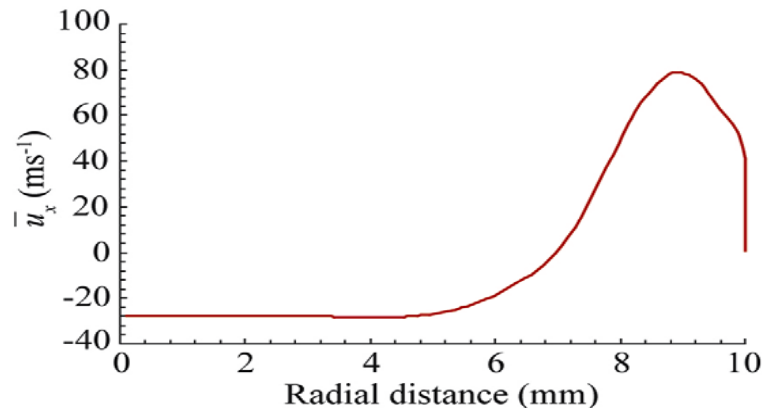

(a)

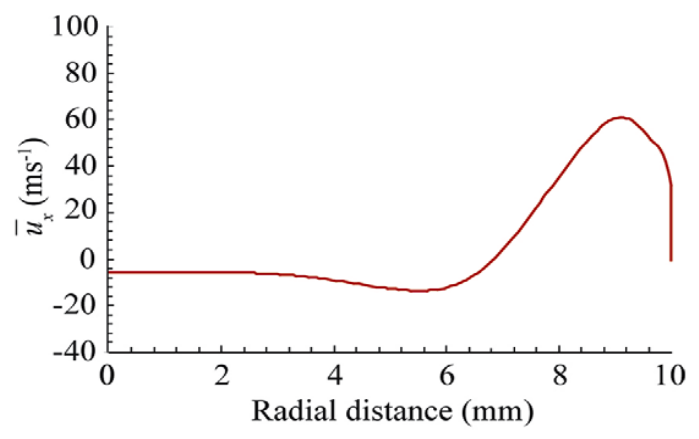

(b)

Figure 8: Radial profiles of axial velocity at (a) $\mathrm{x}=50 \mathrm{~mm}$, (b) $\mathrm{x}=100 \mathrm{~mm}$ [4]

The magnitude of azimuthal velocity was highest while that of radial velocity was found to be insignificantly lowest. Magnitude of azimuthal velocity decreased towards the hot end. Throughout the tube, cold flow in the core axial region was found to have negligible azimuthal velocity (Fig. 9).

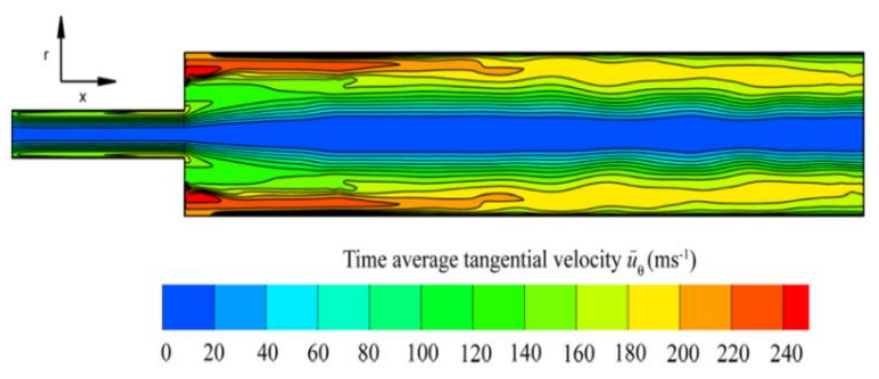

Figure 9: Contours of Azimuthal Velocity [4]

Contours of total temperature indicated warm flow in the peripheral region while cold flow in the core axial region. Maximum total temperature was found to exist near the wall. The total temperature decreased at the tube wall due to no slip boundary conditions (Fig. 10). Authors reported that these predicted profiles of temperature provide indication about kinetic energy distribution in RHVT. The kinetic energy of fluid in the core cold flow region is minimum due to minimum magnitude of azimuthal velocity. When compared, it was found from contours that zone of minimum azimuthal velocity coincided with zone of minimum temperature.

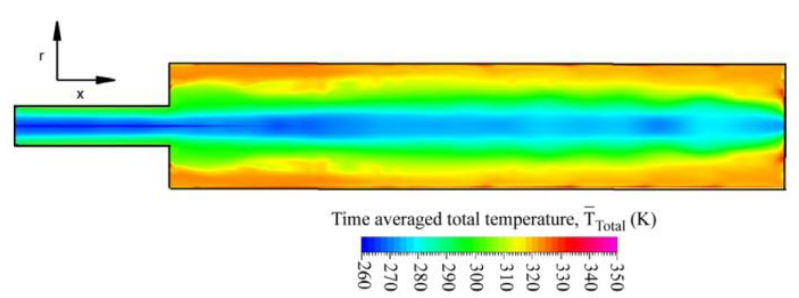

Figure 10: Contours of Time Averaged Total Temperature [4]

From structure of instantaneous streamlines, it was reported that a reversal of the flow occurs in the inner region of RHVT. Vortex structures are observed throughout the tube. Small vortices were observed mostly in the cold (central) region of the tube (Fig. 11). These small vortices were not observed by Aljuwayhel et al. [1] \& Behera et al. [5]

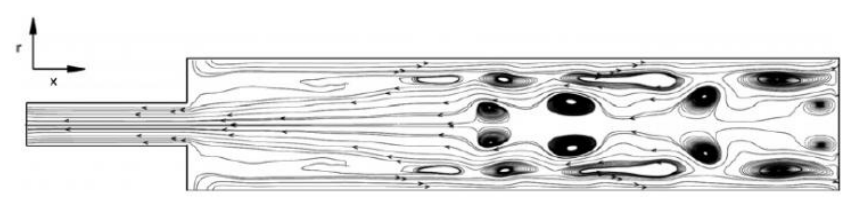

Figure 11: Instantaneous streamlines for RHVT [4]

Upendra Behera et al. [5] used a 3-D CFD model having 0.89 million cells to analyze the flow field of RHVT. Authors reported that drag force caused by the pressure difference between flow field in RHVT and cold end acts continuously on particles moving towards the hot end. When the particle is not left with any momentum to flow against this pressure gradient, its axial velocity ceases to zero and later on reverses its direction of flow, by moving towards the cold end. Further acted by the differential pressure, the particle expands causing to considerable increase in axial velocity in negative direction.

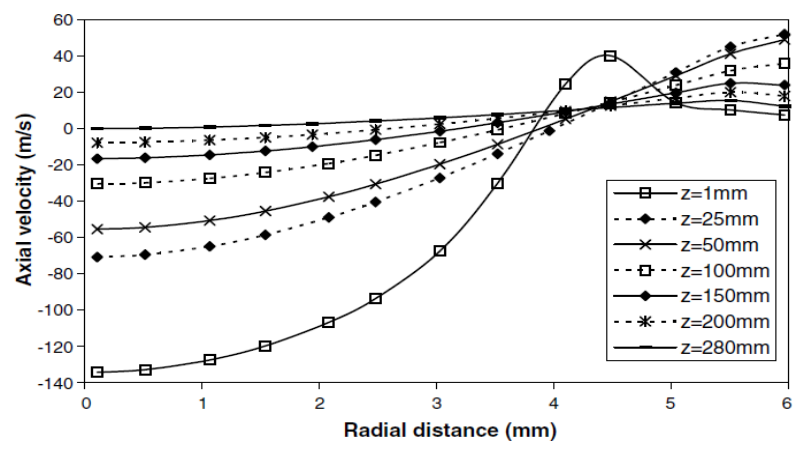

Figure 12: Radial Profile of Axial Velocity [5]

The point, at which thickness of cold exit region comes to zero, i.e. stagnation point, was determined to exist at a distance of about $280 \mathrm{~mm}$ from inlet (Fig. 12). Radial profile of swirl velocity clearly indicated that most of flow inside the tube is governed by forced vortex regime where the swirl velocity is proportional to the radius (Fig. 13). 


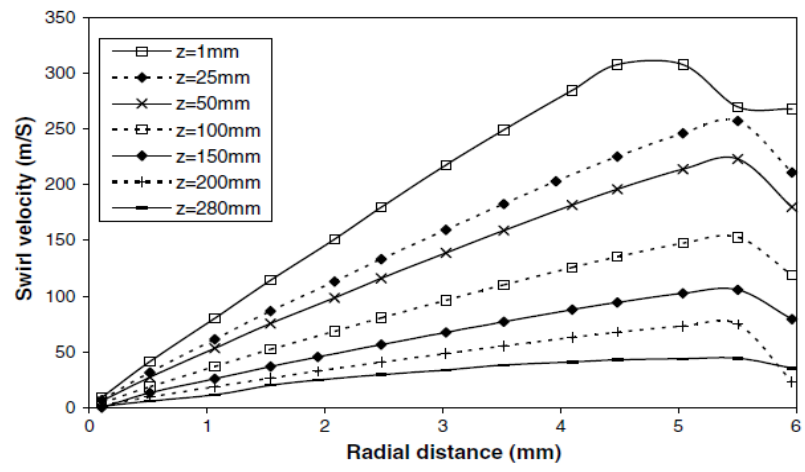

Figure 13: Radial Profile of Swirl Velocity [5]

It was observed that static pressure increases along radial direction at all cross-sections leading to negative radial velocity of the particle. Difference of pressure between peripheral layers to core layers decreases with increasing axial distance from inlet (Fig. 14).

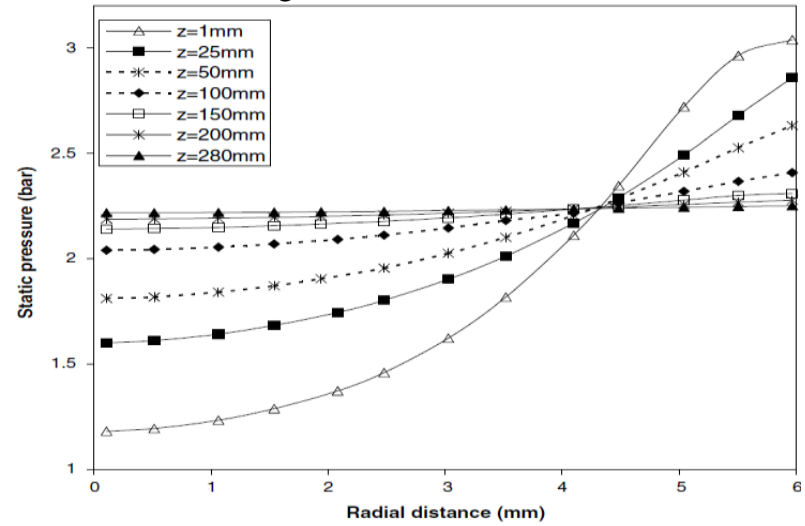

Figure 14: Radial Profile of Static Pressure [5]

This profile indicates that peripheral layers of fluid are in compression while core axial layers undergo expansion. Thus, peripheral layers are heated up while core axial layers are cooled down.

Nader POURMAHMOUD et al. [6] investigated the effect of helical nozzles on temperature separation of RHVT. They used 3-D steady-state axisymmetric computational domain along with periodic boundary conditions for analysis, utilizing both straight and helical nozzles. As the geometry of the RHVT is periodic, only a sector of the flow domain with angle $120^{\circ}$ needed to be considered (Fig. 15).

Authors reported that prediction of the cold exit temperature difference is found to lie between the experimental and computational results of Skye et al. [3]. But, both numerical results of hot exit temperature difference are very closer to experimental data (Fig. 16).

The velocity field indicated that even for 6 straight nozzles, locally injected momentum by means of nozzles into vortex chamber is restricted to nozzle exit area only for 6 nozzles, and it is of low order because of small width of nozzle and division of total mass among the nozzles. This arrangement of nozzles was acceptable only because it helped to create a symmetric flow field.

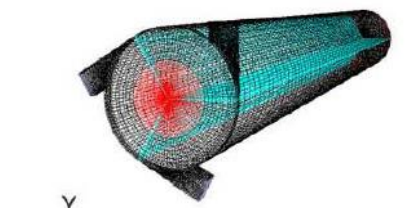

(a)

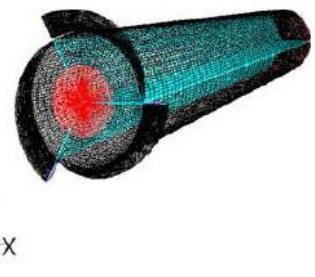

(b)

Figure 15: 3-D CFD Model of RHVT with (a) 3 Straight Nozzles, (b) Helical Nozzles [6]
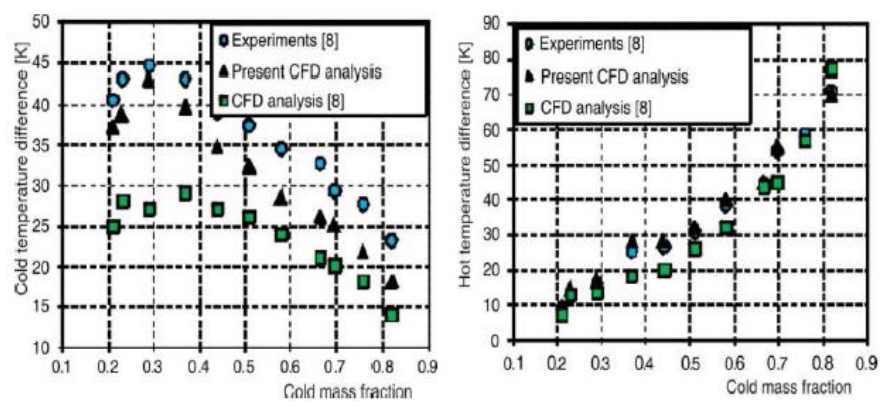

Figure 16: Cold Exit Temperature Difference as a Function of Cold Mass Fraction [6]

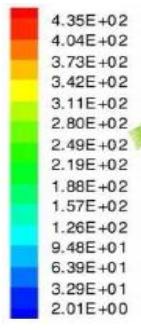

(a)

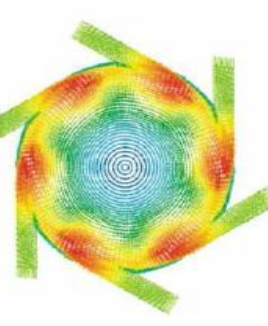

(a)

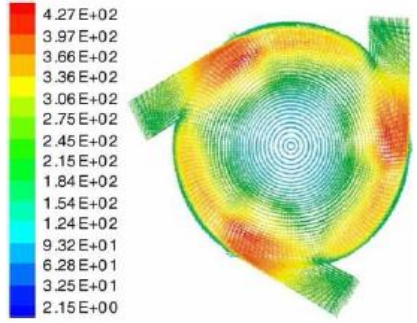

(b)

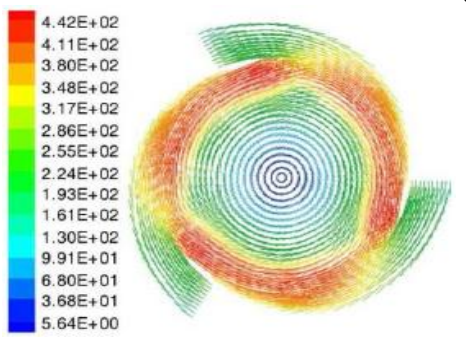

Figure 17: Velocity Patterns at the Vortex Chamber (a) 6 Straight Nozzles (b) 3 Straight Nozzles (c) 3 Helical Nozzles. [6]

The objection of locally momentum injection was recovered by increasing of nozzle width because total nozzles area was constant for all of nozzles set. This situation caused a uniformly injection of momentum to produce semi continues high momentum zones in the rotating flow domain since the nozzles number is less than the last one, so the exit momentum from each nozzle is more effective to move downstream flow toward next nozzle(Fig. 17) .

Applying of 3 helical nozzles removed the issue of instantaneously momentum injection and semi continues high momentum zones in the vortex chamber.

T. Dutta et al [10] used Four Reynolds Average NavierStokes (RANS) based turbulence models, namely the standard $\mathrm{k}-\varepsilon$, RNG $\mathrm{k}-\varepsilon$, Standard $\mathrm{k}-\omega$ and Shear Stress Transport (SST) $\mathrm{k}-\omega$ to model the turbulence present in the flow field of 
RHVT. Their results indicated that difference of pressure between wall and axis are maximum with RNG $\mathrm{k}-\varepsilon$ while it was least for Standard k- $\varepsilon$ model (Fig. 18).

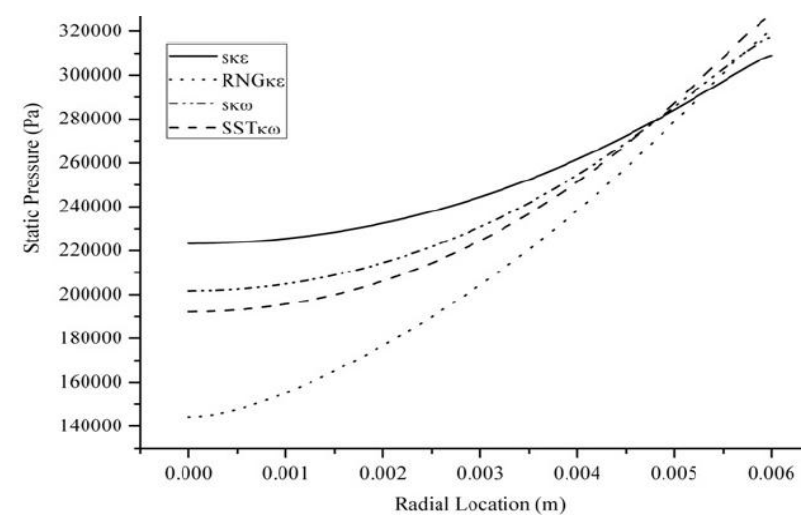

Figure 18: Radial distribution of Static Pressure (Pa) at $\mathrm{z} / \mathrm{L}=0.5[10]$

The magnitude of axial velocity of gas particles flowing towards cold outlet was higher in case of RNG k- $\varepsilon$ model (about $160 \mathrm{~m} / \mathrm{s}$ ) that all other models, as shown in figure 19 . While, the profiles of axial velocity predicted in the near wall region was almost similar for all the models. All the models clearly predicted the phenomenon of reversal of flow which was indicated by negative value of axial velocity. The location of zero axial velocity was almost identical for all the four models.

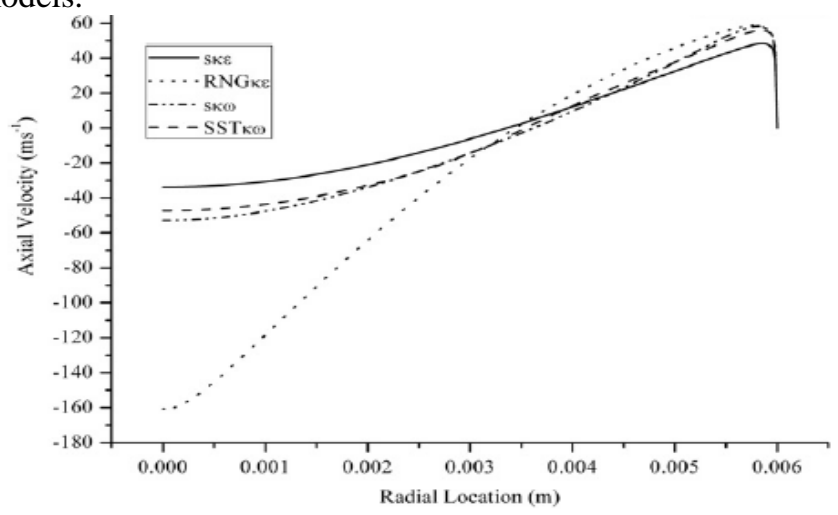

Figure 19: Radial Distribution of Axial Velocity $(\mathrm{m} / \mathrm{s})$ at $\mathrm{z} / \mathrm{L}=0.5[10]$

In case of profiles of static temperature, all the four turbulence models predicted the same qualitative nature; however the magnitude obtained differed considerably. The resulting temperature differential was attributed to difference in predicted pressure differential by various models (Fig. 20).

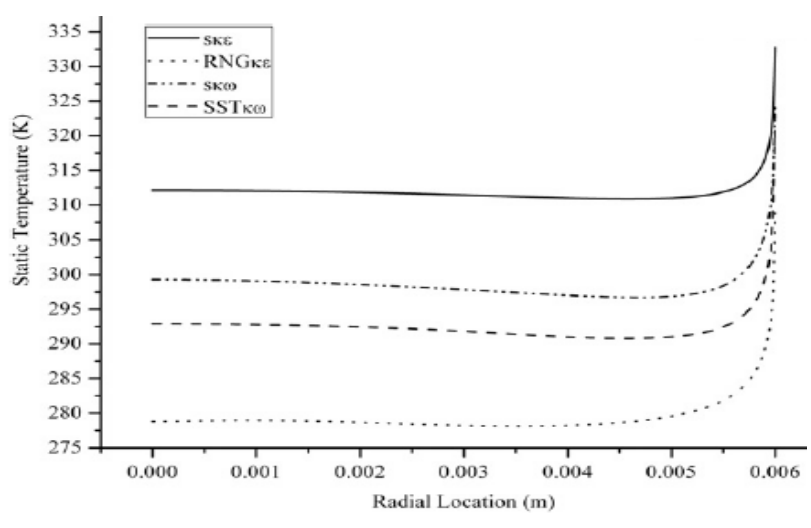

Figure 20: Radial distribution of Static Temperature (K) at $\mathrm{z} / \mathrm{L}=0.5[10]$

\section{CONCLUSION AND FUtURE ENHANCEMENT}

Due to small size, RHVT presents difficulties associated with accurate determination of profiles of temperature and flow field using experimental arrangement. This is where numerical analysis comes to aid of researchers. However, still a lot of discrepancy exists between experimental and numerical results when different turbulence models are employed. Work towards improvement of this situation needs to done.

The flow inside RHVT, being highly turbulent, needs considerable computational power and cost for simulation and study, when using $3 \mathrm{D}$ models. This is the section which provides the scope for enhancement.

The parameters of flow physics taken into consideration for the purpose of review are diversified, which is intended towards avoiding monotonous nature and repetition of presented results and attempts to extract essential and quality outputs from published literature.

\section{REFERENCES}

[1] N.F. Aljuwayhel, G.F. Nellis and S.A. Klein "Parametric And Internal Study Of The Vortex Tube Using A CFD Model", International Journal of Refrigeration, Vol. 28, Pp. 442-450, 2005.

[2] R. Shamsoddini and A.H. Nezhad, "The Numerical Analysis of the Effects of Nozzle Number on the Flow and Power of Cooling of Vortex Tube", International Journal of Refrigeration, Vol. 33, Pp. 774-782, 2010.

[3] H.M. Skye, G.F. Nellis and S.A. Klein, "Comparison of CFD Analysis to Empirical Data in A Commercial Vortex Tube", International Journal of Refrigeration, Vol. 29, Pp.71-80, 2006.

[4] T. Farouk and B. Farouk, "Large Eddy Simulations of the Flow Field and Temperature Separation In The Ranque-Hilsch Vortex Tube", International Journal of Heat and Mass Transfer, Vol. 50, Pp. 47244735, 2007.

[5] U. Behera, P.J. Paul, K. Dinesh and S. Jacob, "Numerical Investigations on Flow Behaviour and Energy Separation in Ranque-Hilsch Vortex Tube" International Journal of Heat and Mass Transfer, Vol. 51, Pp. 6077-6089, 2008.

[6] N. Pourmahmoud, A.H. Zadeh, O. Moutabay and A. Bramo, "Computational Fluid Dynamics Analysis of Helical Nozzles Effects on Energy Separation in a Vortex Tube", Thermal Science, Vol. 16, No. 1, Pp. 151-166, 2012.

[7] A. Secchiaroli, R. Ricci, S. Montelpare and V. D'Alessandro, "Numerical Simulation of Turbulent Flow in A Ranque-Hilsch Vortex Tube", International Journal of Heat and Mass Transfer, Vol. 52, Pp. 5496-5511, 2009.

[8] Ons TLILI EL MAY, Ines MOKNI, Hatem MHIRI and Philippe BOURNOT, "CFD Investigation Of A Vortex Tube: Effect Of The Cold End Orifice In The Temperature Separation Mechanism", Science 
Academy Transactions on Renewable Energy Systems Engineering and Technology (SATRESET), Vol. 1, No. 3, September 2011, ISSN: 20466404.

[9] Smith Eiamsa-ard and Pongjet Promvonge, "Numerical Investigation Of The Thermal Separation In A Ranque-Hilsch Vortex Tube", International Journal of Heat and Mass Transfer, Vol. 50, Pp.821-832, 2007.

[10] T. Dutta, K.P. Sinhamahapatra and S.S. Bandyopdhyay, "Comparison Of Different Turbulence Models In Predicting The Temperature Separation In A Ranque-Hilsch Vortex Tube", International Journal of Refrigeration, Vol. 33, Pp. 783-792, 2010.

[11] W. Frohlingsdorf and H. Unger, "Numerical Investigations of the Compressible Flow and the Energy Separation in the Ranque-Hilsch Vortex Tube, International Journal of Heat and Mass Transfer, Vol. 42 Pp. 415-422, 1999.

[12] K. Stephan, S. Lin, M. Durst, F. Huang and D. Seher, "An Investigation of Energy Separation in a Vortex Tube", International Journal of Heat and Mass Transfer, Vol. 26 (3), Pp. 341-348, 1983.

[13] C.M. Gao, K.J. Bosschaart, J.C.H. Zeegers and A.T.A. M De Waele, "Experimental Study On A Simple Ranque-Hilsch Vortex Tube", Cryogenics, Vol. 45, Pp. 173-183, 2005.

[14] U. Behera, P.J. Paul, S. Kasthurirengan, R. Karunanithi, S.N. Ram, K. Dinesh and B. Jacob, "CFD Analysis And Experimental Investigations Towards Optimizing The Parameters Of Ranque-Hilsch Vortex Tube", International Journal of Heat and Mass Transfer, Vol. 48, Pp. 19611973, 2005.

[15] BK Ahlborn and JM Gordon, "The Vortex Tube as a Classical Thermodynamic Refrigeration Cycle", Journal of Applied Physics, Vol. 88 Pp. 3645-53, 2000.

[16] PM Silverman, "The Vortex Tube: A Violation of the Second Law?" European Journal of Physics, Vol. 3, Pp. 88-92, 1982.

[17] B Ahlborn and S Groves, "Secondary Flow in a Vortex Tube", Fluid Dynamics Research, Vol. 21, Pp. 73-86, 1997. 